\title{
Employer Perceptions and Implementation of Commute Alternatives Strategies
}

Kai Zuehlke and Randall Guensler, Georgia Institute of Technology

\begin{abstract}
Employer-based trip reduction (EBTR) strategies are the transportation demand management elements of commute options programs that target commute travel. This article reports the results of two surveys conducted in the Atlanta metropolitan area of implementation of EBTR strategies and employer perceptions of associated costs and benefits. On average, less than a quarter of the employers surveyed utilized EBTR strategies. Survey results indicate that employers commonly perceive that EBTR strategies provide minimal benefits for the company, that employers believe their employees lack interest in such measures, and that upper management does not provide support. Employers regard the distance between work location and transit as a significant barrier to implementing EBTR programs, and onsite sale of transit passes is associated with cost, equity, and operational concerns. However, members of transportation management associations and Atlanta's Clean Air Campaign report higher levels of implementation.
\end{abstract}

\section{Introduction}

Transportation demand management (TDM) can mitigate congestion and improve air quality by reducing the impact of individual travel decisions. Many TDM strategies do this by causing commuters to utilize alternatives instead of driving alone during peak periods. TDM organizations can urge individuals to par- 
ticipate in TDM programs via mass media campaigns and encourage employers to adopt TDM strategies through employer outreach.

This article examines the implementation of various employer-based trip reduction (EBTR) strategies among a sample of employers in the Atlanta metropolitan area. The Atlanta Clean Air Campaign (CAC) manages and publicizes various TDM programs and local transportation management associations (TMAs) support EBTR strategies. A large portion of employer membership in either of these organizations could indicate a high degree of employer outreach in the region. Employer promotion of TDM programs could indicate a degree of employer commitment to EBTR. Employers making alternative work modes available and offering commute benefits to employees would indicate a high degree of EBTR strategy implementation.

Approximately 15 percent of employers surveyed are members of either the CAC or a TMA, and at least 20 percent of employers promote commute programs at least rarely. Almost 80 percent of employers have a 40 -hour workweek available to all employees, about 25 percent of employers make flexible scheduling available to all employees, and other work modes are less available. On average, less than 15 percent of employers offer commute benefits.

This article addresses whether employer outreach actually leads to implementation of EBTR strategies. Members of CAC/TMAs achieve higher levels of implementation and have more positive employer perception of employer trip reduction programs than nonmembers. Noting this success, but acknowledging the potential influence of other factors, this article further explores barriers employers perceive as impeding implementation of EBTR strategies.

Survey results indicate that employers commonly perceive minimal benefits of, believe their employees lack interest in, and feel that upper management do not provide support for employer trip reduction programs. Employers regard the distance between their work location and transit as a significant barrier to implementing trip reduction programs. Implementation of onsite sales of transit passes is also associated with increased employer perception of conflict with organization operations, high cost, and concerns regarding equity across types of employees.

To understand the implications of these general results, the next section chronicles the history of employer-based TDM in the United States, and then discusses the local context of TDM and EBTR in Atlanta. The conceptual framework section defines the scope of this article; the methodology section covers the survey design, 
response rates, and analytical approach. Next, the levels of implementation of a wide set of EBTR strategies are presented, followed by the effect of CAC/TMA membership on EBTR strategy implementation. The barriers section uncovers obstacles employers perceive as impeding EBTR strategy implementation. The conclusions drawn are presented in the final section.

\section{Employer Transportation Demand Management}

TDM seeks to reduce congestion and improve overall mobility by influencing individual travel behavior. Various elements of U.S. transportation planning and policy have served this function. Following the major freeway construction boom of the 1950s and 1960s, transportation planning efforts turned in the 1970s toward increasing effective highway vehicle-carrying capacity and transit system performance without large federal capital expenditures. Parallel concerns sparked by the series of Clean Air Act Amendments and the oil price hikes led to efforts to manage transportation systems in the interest of air quality and energy efficiency and security, respectively (Meyer 1999). Thus, TDM incorporates aspects of congestion mitigation, air quality, and energy conservation. Rye (1999b) also points out the important roles employer-specific TDM can play in growth management, business development, and employee recruitment and retention.

A primary means of managing transportation demand is reducing the proportion of trips made by single occupancy vehicle, which would be measurable by a reduction in vehicle miles traveled (VMT). Work commute trips by automobile represent 20-25 percent of all trips made in the United States, are concentrated in the congested peak periods, and tend to be predominantly single occupant (Horner 2004). Given significant average geographic separation between home and work, influencing the travel demand of commuting employees could have the potential to greatly reduce VMT in the critical periods. Engaging employers is a primary means of achieving this reduction in commute travel.

TDM initiatives directed at employers have many different labels. Starting with aspects of early traffic management and transportation system management, more recent terms include employer-based TDM, employer trip reduction programs, EBTR strategies, employer commute options programs, employer-based travel plans, employer transport plans, mobility management, green commuter plans, and green transport plans (Meyer 1999; Rye 1999a, 1999b). Regardless of the moniker, EBTR strategies utilize employers as "mediating institutions" for public 
policy (Dehart-Davis and Guensler 2005). EBTR strategies can be similarly viewed as social marketing (McGovern 2005) specifically targeting employers. More can be found on EBTR strategies in Institute of Transportation Engineers and COMSIS Corporation (1993), Meyer (1997, 1999), Hendricks and Joshi (2004), and Henry and Gordon (2003).

Given the societal importance and costs of work-related travel, the goal of EBTR strategies may be "to encourage more employers to take responsibility for the congestion and pollution generated by their employees' trips to, from, and at work" (Rye 1999b). That is, EBTR strategies urge employers to internalize the externalities of commute travel. This is no easy task, given bureaucratic, corporate, and organizational tendencies for self-interest.

Serious challenges confront the acceptance, implementation, and success of EBTR strategies (Higgins 1996; Meyer 1999; Rye 1999a, 1999b). Limited success of early, mandatory EBTR programs has underscored the importance of inclusive planning processes in formulating EBTR strategies and implementation goals (Guensler 1998; Dill 1998). Automobile reliance, low-density suburban land-use patterns, and modest transit service have the potential to discourage U.S. employers from accepting EBTR strategies. Yet one recent study has shown that EBTR strategies can benefit employers' bottom line, requiring only a change of mindset and a commitment (Winters, Hendricks, and Stutts 2003).

When employers do embrace EBTR strategies, researchers are challenged with determining program effectiveness. Reduction in the drive-alone rate relative to a pretest or control group is one measure of program effectiveness (Higgins 1996). However, such data are rarely collected. A "performance measure continuum" that captures both the social acceptance of and quantifiable change in travel behavior has been proposed to evaluate EBTR project and program effectiveness (Finke and Schreffler 2004) and has been applied to Atlanta (Center for Transportation and the Environment 2003).

\section{Atlanta Context}

Atlanta has faced increasing transportation and air quality problems in recent decades, culminating in noncompliance with federal Clean Air Act standards. Public interest group reports gave the perception that Atlanta's traffic congestion and air quality issues were negative quality-of-life indicators, which could discourage businesses and employees from locating in the region. In this environment, business leaders and policy-makers were eager to employ innovative measures 
to address transportation issues. A major initiative started during this time is the Atlanta Framework for Cooperation to Reduce Traffic Congestion and Improve Air Quality, a collaboration among planning agencies, business groups, and transportation management associations (Clean Air Campaign 1999).

The Atlanta Framework envisions a multifaceted campaign to "improve the Atlanta Region's Air Quality and Mobility through the coordinated programs of public and private organizations designed to change individual and employer behaviors" (Clean Air Campaign 1999). Employer-based strategies and mass media publicity supplement commute services to individuals. Programs available to individuals include 1-87-RIDEFIND, which matches interested carpoolers, and guaranteed ride home (GRH), which guarantees ridesharing employees a trip home under emergency circumstances. The CAC coordinates TDM efforts regionally in conjunction with local TMAs and serves the public relations function of the Atlanta Framework by encouraging employers to adopt trip reduction strategies (see http://www.cleanaircampaign.com/ - July 2007). The Atlanta Framework utilizes many EBTR strategies, including carpools, vanpools, sales and subsidies of transit passes, GRH, flexible and compressed scheduling, and telework.

Results presented in this article afford unique insight into employer participation in and perception of EBTR strategies among a sample of Atlanta employers. The goal of this research is neither to determine the effectiveness of the Atlanta Framework in recruiting employers nor to gauge the resulting amount of travel reduction. The performance of the Atlanta Framework has been evaluated previously for an earlier time period (Center for Transportation and the Environment 2003) and is currently being evaluated again. Instead, this article examines the level of implementation of a variety of EBTR strategies across time. Using employer mail surveys, EBTR strategy implementation rates are assessed and barriers are identified. Before presenting an overview of the methodology of this study, the next section frames the scope of analysis.

\section{Conceptual Framework}

A major thrust of the Atlanta TDM Framework is to urge commuters to choose commute alternatives instead of driving alone during peak periods. Efforts in individual and employer outreach can be conceptualized according to Figure 1. "Awareness" indicates knowledge of TDM strategies and "participation" means commute benefit utilization, alternative work mode selection, and/or TDM program enrollment. 


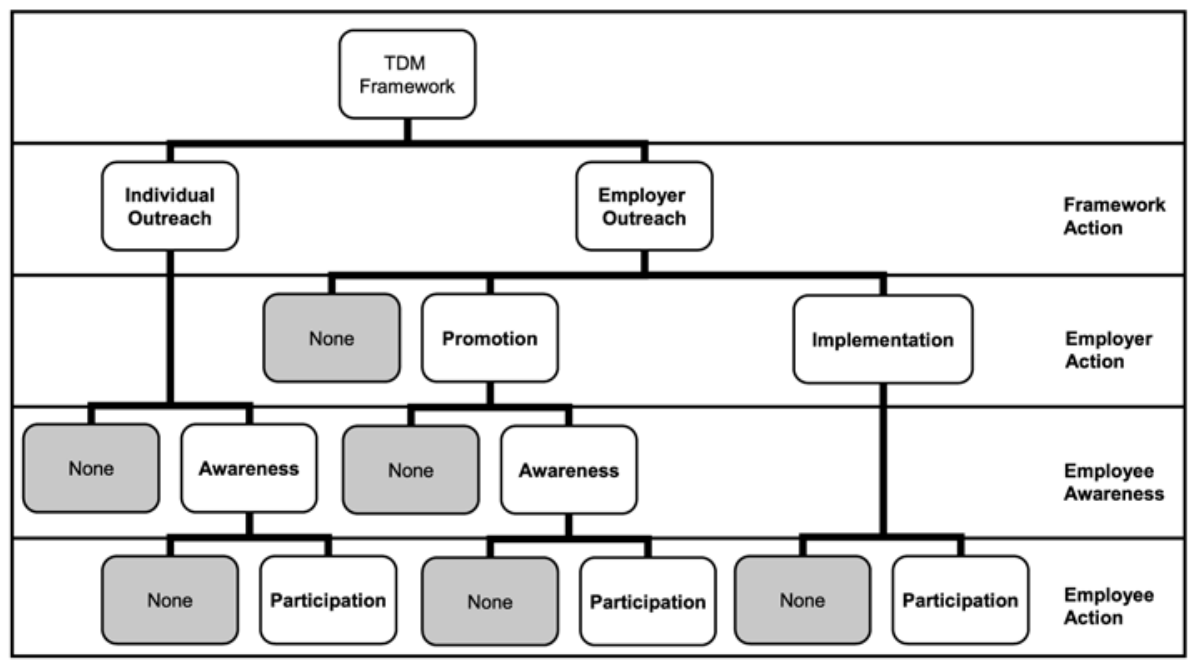

Figure 1. Employer Role in TDM

Sometimes simply informing individuals is sufficient to induce program participation. Assuming complete information dissemination, individuals would evaluate their commute choice set considering factors such as proximity to transit and service attributes through the filter of personal bias or predisposed disinclination. A subset of aware individuals would choose to participate in TDM programs. Participation in TDM programs would entail use of commute alternatives, which would then result in some travel and emissions changes (presumably reductions). On this "individual" branch of the TDM tree, other possible outcomes are awareness without participation and media publicity without awareness.

To capture commuters not recruited to TDM program participation by individual outreach, regional TDM organizations engage in employer outreach. The added mediation and social marketing provided by employers are presumed to increase the likelihood of individual commuters participating in TDM programs. Employers could balance factors such as transit proximity to their location, work-site operations, and employee characteristics through the lens of institutional bias. Employers engaged by the CAC/TMAs might choose to promote employees to ongoing regional programs and systems, such as transit, rideshare matching service, GRH, or financial incentives. This added marketing could cause awareness in commuters 
not reached by mass media marketing. A subset of such aware individuals might choose to participate.

Still, informational awareness would only induce a certain percentage of commuters to modify their travel behavior. Capturing more intrepid drivers would require tougher measures, such as not merely promoting existing regional TDM programs but implementing onsite TDM strategies. This could include actual coordination/facilitation of work-site programs, additional incentives, and modification of work schedules. Except for possibly during the brief stint of mandatory EBTR programs (Guensler 1998; Dill 1998), even employer implementation of TDM strategies would not result in 100 percent employee participation. To summarize the "employer" tree, the additional options include employer program implementation without employee participation, employer program promotion without employee awareness, employee awareness without employee participation, and complete employer nonparticipation. ${ }^{1,2}$

This article primarily assesses employer TDM strategy implementation and the impact of effective employer outreach, as measured by membership in the CAC/ TMAs, on strategy implementation. Given the challenges of inducing employers to CAC/TMA membership and EBTR strategy implementation, employer-perceived barriers are examined.

\section{Methodology}

\section{Survey Design}

This article presents data from the Atlanta Employer Commute Options (ECO) Survey, which was conduced in 2003 and 2005 as a part of the Commute Atlanta project (see http://commuteatlanta.ce.gatech.edu/ - July 2007). Commute Atlanta is an ongoing congestion pricing research project that uses GPS-instrumented vehicles to study driver behavior and consumer response to mileage-based and real-time congestion pricing ( $\mathrm{Li}$ et al. 2004; Ogle 2005). The employer survey element was designed to control for changes in employer policies and practices that might impact trip-making behavior during the Commute Atlanta study period. The survey data provide insight into employer perception and implementation of EBTR strategies across two phases: 2003 and 2005. This time period was selected due to the Commute Atlanta project schedule and not due to any specific treatment presumed to have particular impact. 
The survey design and strategies included in the survey were developed in consultation with an expert survey advisory panel (Dehart-Davis and Guensler 2005; Dehart-Davis, Feng, and Guensler 2004; Feng, Dehart-Davis, and Guensler 2005). The original survey sample was drawn from 207 employers of Commute Atlanta households, a random selection of 300 members of the Metro Atlanta Chamber of Commerce (MACOC), and a random selection of 300 employers of 4,000 household participants in the Strategies for Metropolitan Atlanta's Regional Transportation and Air Quality (SMARTRAQ) regional travel diary study (Dehart-Davis, Feng, and Guensler 2004; Feng, Dehart-Davis, and Guensler 2005). The ECO survey was mailed to the human resources director of each employer, as the director was believed to be the best person within the organization to know the employee transportation policies of the organization. An alert letter preceded the printed survey, cover letter, postage-paid return envelope, and a small monetary incentive. If, after a follow-up postcard, there was still no response, a second survey was sent with a new cover letter and return envelope. For businesses that were members of the chamber of commerce, a third mailing was addressed to the CEO with a cover letter from the MACOC president. Employer identification numbers enabled positive employer identification and tracking of all employers across phases.

Scrutiny of the mail survey returns warranted exclusion of 44 employers believed to have never received any survey mailing in either phase. Of employers that completed a survey in Phase 1, 34 either relocated or went out of business between phases and were consequently excluded from the Phase 2 potential sample pool. After the analysis was completed, it was discovered that accidental multiple polling of several work sites yielded cases of multiple returned surveys for a single employer. The same employer was coded in separate records due to redundancy across the data sources. Most duplication appeared in pairs, with two cases of three records representing a single employer. Cleaning the dataset resulted in removing 19 records; 10 cases of two-phase nonresponse (no data lost), 7 cases of one-phase nonresponse (one phase of results lost), and 1 case of two-phase response (both records deleted). ${ }^{3}$

\section{Response Rates}

After data cleaning, in Phase 1 (2003), 35 employers declined to participate (5\%), 297 employers did not respond (40\%), and 406 employers completed the survey (55\%), resulting in a response rate of 58 percent. In Phase 2 (2005), 24 employers declined to participate (3\%), 338 did not respond (48\%), and 343 employers completed the survey (49\%), yielding a 59 percent response rate. The sample of com- 
pleted surveys consisted of 172 employers that responded only in Phase 1 (34\%), 109 only in Phase 2 (22\%), and 225 that responded in both phases (44\%).

Figure 2 maps the locations of the ECO survey employers. The geographic distribution of employers was determined by categorization of geocoded addresses into three location types. Employers were assumed to be located in a high-density "rail core" if they were within a 0.25 -mile radius of a heavy rail station $(n=89,12 \%)$. Employers within 0.25 straight miles of any transit line (heavy rail, express bus, and local bus) were considered within a "transit zone" ( $n=431,58 \%)$. Other employers in the sample were labeled "non-transit zone" ( $n=222,30 \%)$. The results are used in the analysis of barriers to EBTR implementation below.

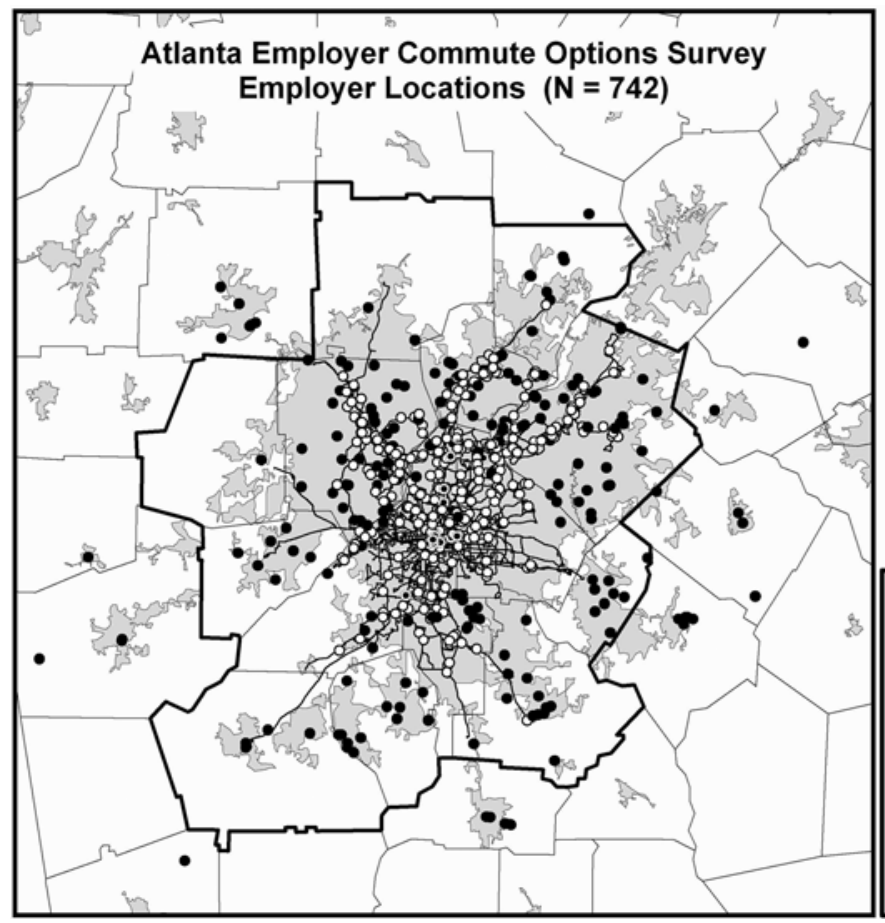

Transit Accessibility Classification Zones

Rail Core:

0.25 miles of rail stations

Transit Zone:

0.25 miles of transit routes

Non-Transit Zone:

Other urbanized and

non-urbanized area

Service Providers:

MARTA

Clayton County Transit

Cobb Community Transit

GRTA Xpress

Gwinnett County Transit

Figure 2. Surveyed Employer Locations

Individual respondents and/or organizations with a higher regard for EBTR strategies might have more readily returned surveys, resulting in self-selection bias. However, given the relatively low frequency of EBTR implementation reported, this seems 
unlikely to have had much impact. Because the Atlanta ECO survey targeted more than 700 employers from three randomized sources and achieved response rates of 50 percent or better, the survey sample is considered reasonably representative of Atlanta employers. See a discussion on potential sample bias in Feng, Dehart-Davis, and Guensler (2005).

Analytical Approach The survey contains nearly 200 different data elements. Subquestion nonresponse was resolved by filtering out records that contain blank values in any field directly relevant to each analysis. Survey questions include binary, categorical, ordinal, and numeric data types on employer characteristics, opinion, metrics, and EBTR strategy implementation. Comparison of binary variables allow for chi-square $\left(\chi^{2}\right)$ testing of statistical significance using $2 \times 2$ contingency tables. With these one degree-of-freedom tables and $\alpha=0.05$, the critical $\chi^{2}=3.841$.

\section{Longitudinal Frequencies}

No statistically significant change in CAC/TMA membership, EBTR strategy promotion, or EBTR strategy implementation was detected between the surveys.

\section{CAC and TMA Membership}

Figure 3 illustrates that membership in the CAC and TMAs averages less than 15 percent of employers. Membership in "either" organization is used in the membership-benefit analysis below. Employer outreach as measured by CAC or TMA membership has not engaged a large portion of the survey sample.

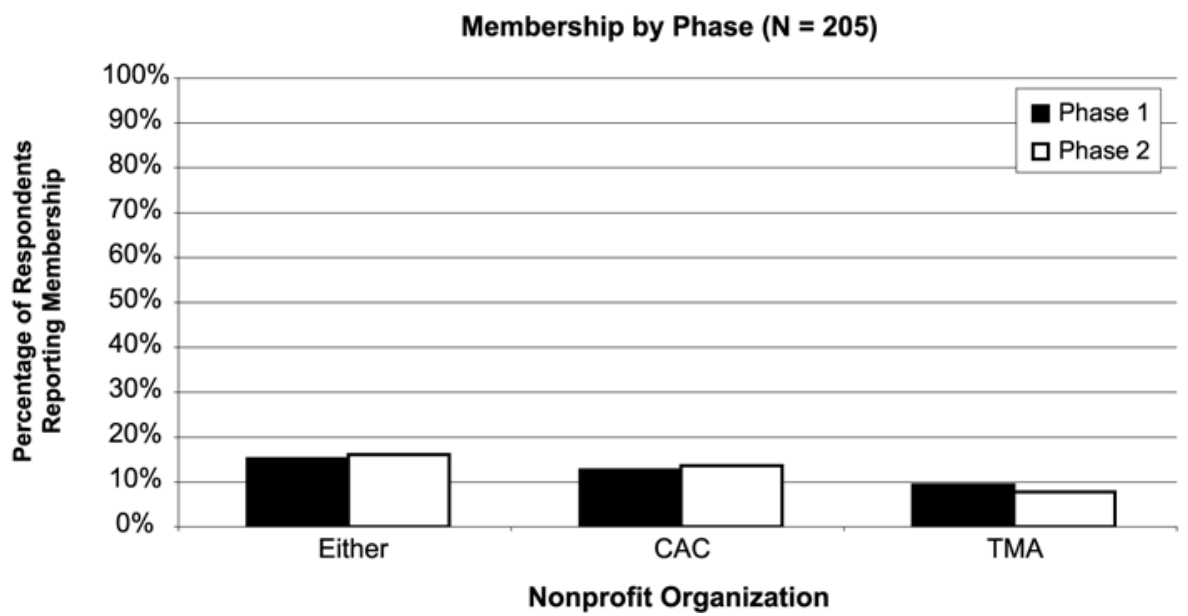

Figure 3. Membership by Phase 


\section{Program Promotion}

Frequency of commute options program promotion serves as an indicator of EBTR prevalence. Promoting programs could enable employers to support ongoing regional EBTR strategies without necessarily bearing direct responsibility. These more "hands-off" approaches include providing information about public transit routes and fares, GRH, and 1-87-RIDEFIND (see Figures $4 a$ and $4 b$ ). Less than 30 percent of surveyed employers promote each of the three programs referenced below.

Frequency of Program Promotion in Phase $1(\mathrm{~N}=\mathbf{2 3 1})$

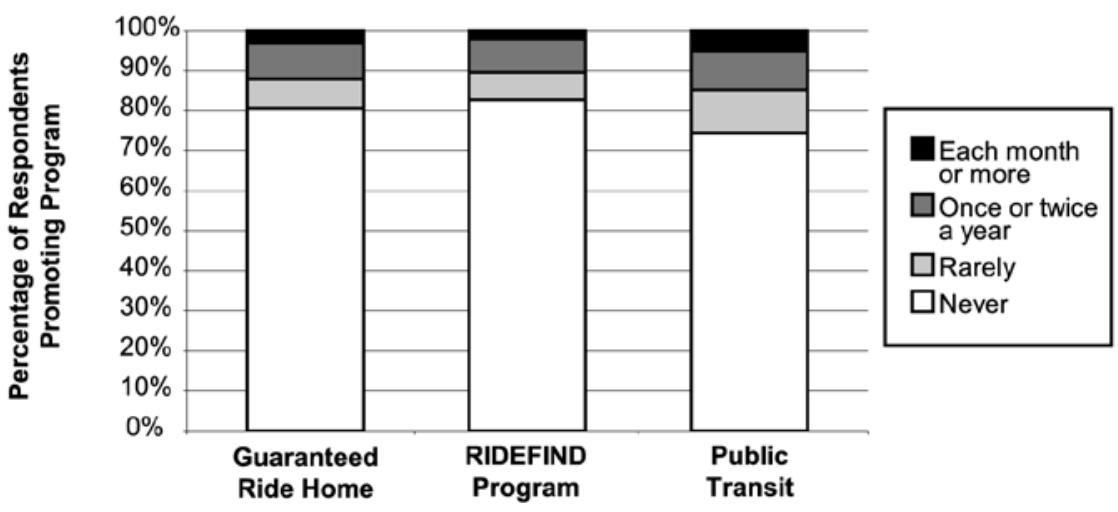

Figure 4a. Program Promotion in Phase 1

Frequency of Program Promotion in Phase $2(\mathrm{~N}=\mathbf{2 3 1})$

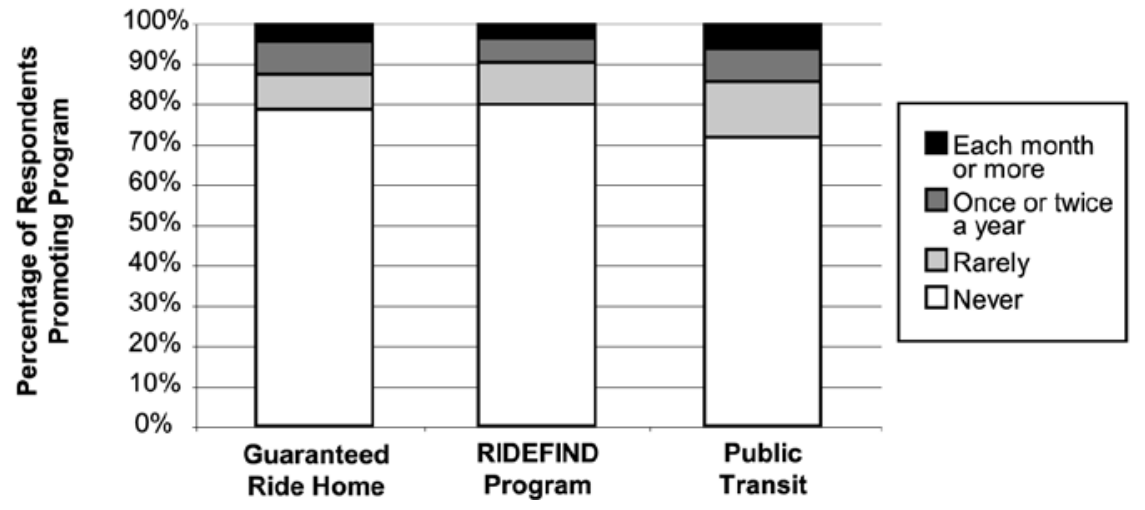

Figure 4b. Program Promotion in Phase 2 


\section{Work Mode Availability}

Offering alternative work modes, though dependent in part on the type of employment, indicates a significant commitment by the employer and represents another key EBTR variable. These include: traditional 40-hour onsite workweek, compressed workweek, multiple work shifts, flexible arrival/departure times, and working from home (see Figures $5 a$ and $5 b$ ).

Clearly, the traditional 40 -hour workweek is the dominant work mode, with flexible arrival and departure times the second most available.

\section{Benefits Offering}

Both in 2003 and in 2005, employers were asked if they offered the following commute benefits:

- Participation in GRH

- Onsite sales of transit passes or tokens

- Employer-subsidized bus, rail, or vanpool passes

- Deductions of carpool, vanpool, or transit expenses from employee pretax income

- Deductions of parking expenses from employee pretax income

- Brokering of discount bus, rail, or vanpool passes

- Bicycle lockers

- Showers for employees biking or walking to work

- Satellite offices from which employees can work

$\mathrm{GRH}$ indicates an employer's estimate of employee participation in the regional program. Bicycle lockers, showers, and satellite offices represent investments committed by employers that could benefit employees choosing commute alternatives. The remaining benefits represent TDM strategies implemented by the employer. 
Work Mode Availability in Phase 1 ( $N=199)$

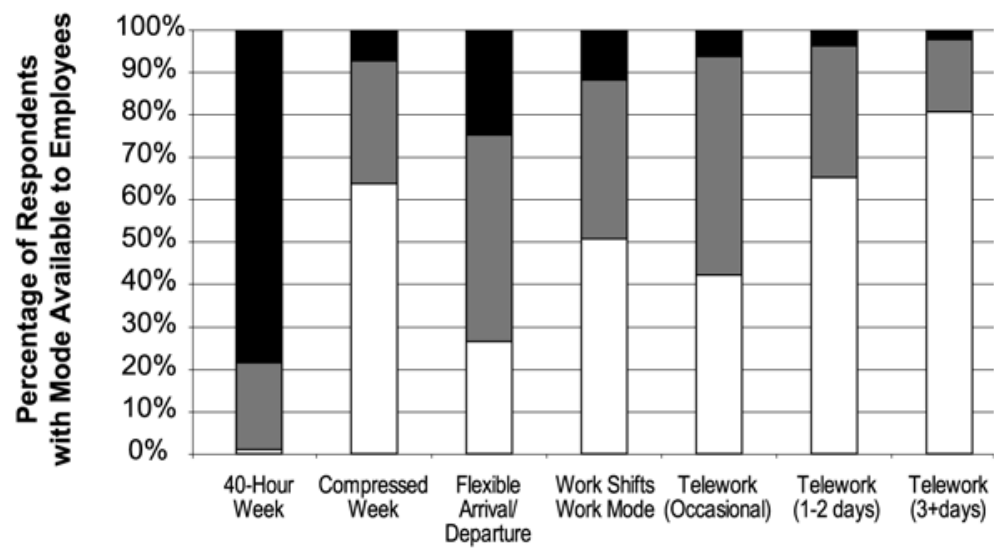

all

$\square$ Some

$\square$ Not

\section{Work Mode}

Figure 5a. Work Mode Availability in Phase 1

Work Mode Availability in Phase 2 ( $\mathrm{N}=199)$
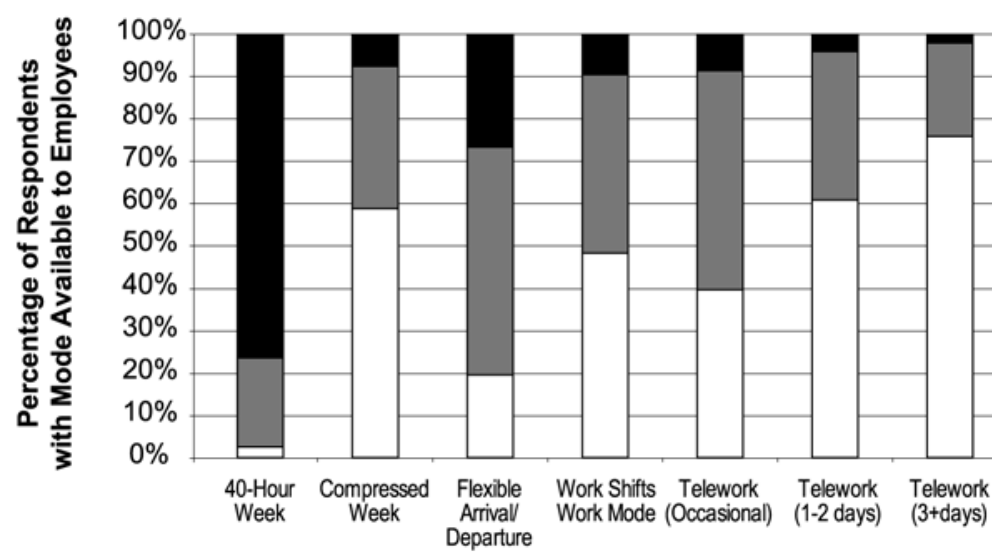

Work Mode

Figure 5b. Work Mode Availability in Phase 2 
Figure 6 charts percentages of respondents offering the benefit in each phase. Most commute benefits are offered by 5 to 15 percent of respondents.

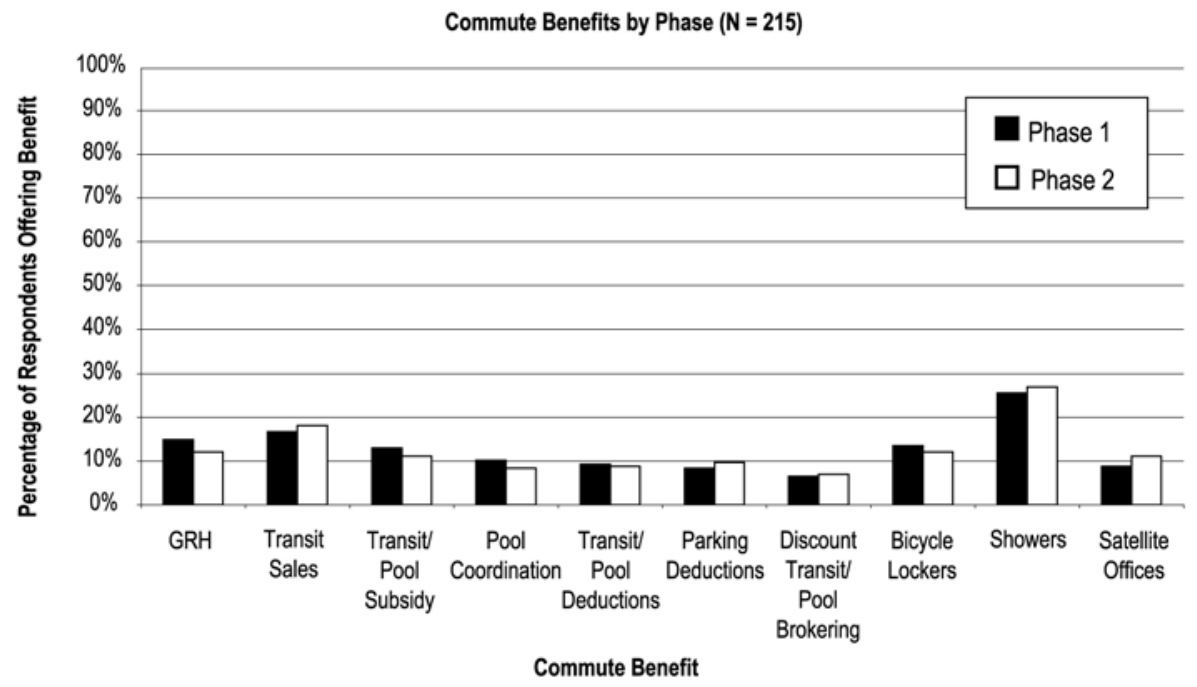

Figure 6. Benefits Offered by Phase

The longitudinal analysis indicates the implementation penetration rates for EBTR strategies by surveyed Atlanta employers may not have changed significantly between survey years. A further key question, however, pertains to whether employer outreach actually leads to employer implementation of TDM strategies.

\section{CAC and TMA Membership}

Figure 7 charts the respective percentages of respondents offering commute benefits by member or nonmember status along with 95 percent confidence intervals. Members of the CAC/TMA are more likely to offer every commute benefit in both phases, except for satellite offices in Phase 1. Also, members are more likely to offer onsite sales of transit passes ( $56 \%$ in Phase $1,54 \%$ in Phase 2 ) than parking deductions ( $25 \%, 26 \%$, respectively) and satellite offices ( $15 \%, 24 \%$, respectively). 


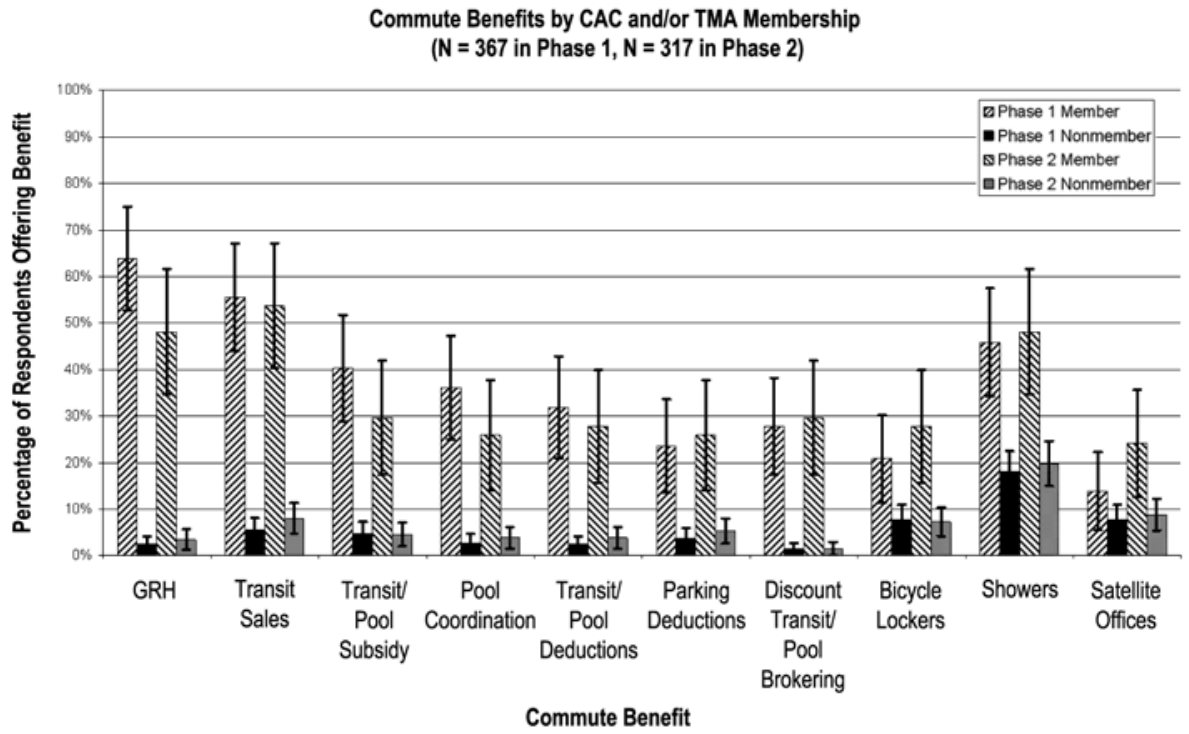

Figure 7. Benefits by CAC/TMA Membership

As further indication of the strength of CAC/TMA EBTR programs, members are more likely to offer transit passes than pretax deductions of parking expenses.

That members of the CAC/TMAs implement EBTR strategies so much more than nonmembers is not necessarily a given and is encouraging to verify. Self-selection is inherent in the very nature of voluntary TDM program participation. However, recruiting more employers to the CAC and TMAs could enhance EBTR program implementation in the region. CAC employees are meeting with strategically targeted employers in a recent aggressive recruitment effort.

Despite the high level of EBTR strategy implementation by CAC/TMA members, most employers surveyed are not members and do not implement EBTR strategies. The next section analyzes employer trepidation to EBTR strategy implementation in terms of perceived barriers. 


\section{Strategy Implementation Barriers}

The survey asked employers the general question, "How influential have the following factors been in preventing your organization from implementing more employee commute options?"

- Insufficient employee interest

- Minimal perceived benefits to organization

- Lack of upper management interest

- Potential regulatory or legal barriers

- Potential conflicts with organization operations

- Potential union opposition or conflicts

- High cost to the organization

- Equity issues across types of employees

- Lack of commute options information

- The office's distance to public transit

- Lack of government incentives

- Potential paperwork requirements

The key question was, "If a company did not offer a commute benefit, what was the potential barrier?" The discussion below focuses on the three major findings: (1) the most commonly perceived barriers, (2) the strength of perceived distance to transit as a barrier, and (3) barriers to onsite sale of transit passes.

\section{Influential Barriers}

For each commute benefit, the percentages of employers not offering the benefit and also considering each barrier as influential were calculated. Each barrier's percentages were averaged across all commute benefits. Under such consideration, the most influential barriers are:

- Insufficient employee interest (62\% in Phase 1,60\% in Phase 2)

- Minimal perceived benefits to organization (54\%,58\%)

- Lack of upper management support $(52 \%, 49 \%)$

- Office's distance to public transit $(51 \%, 43 \%)$

Survey respondents indicate significant resistance to implementing EBTR strategies when they report lack of employee interest from below, lack of upper manage- 
ment support from above, and minimal perceived benefits across the organization.

\section{Distance to Transit}

The second major finding is the strength of distance to transit as a barrier to major EBTR commute benefits in both phases: GRH, transit sales, transit/vanpool/carpool subsidy, deductions of transit/pool and parking expenses, and brokering of discount transit/pool passes. Table 1 indicates $\chi^{2}$ statistical difference for influence of distance to transit on not offering these commute benefits. Two other statistics demonstrate the importance of this barrier: difference and consistency factors. The difference factor, $\delta$ percent, indicates the raw difference between the percentage of respondents who do not offer the commute benefit that report the barrier as influential and the percentage of respondents who do offer the commute benefit that report the barrier as influential. A large positive value for the difference factor for barriers indicates the potential presence of a persuasive and preventative barrier. The "consistency factor," c, is one additional dispersion statistic that relates the total number of employers who indicate barrier influence to how many end up not offering the benefit. Low values of this percentage would indicate a high level of consistency and a strong explanatory value. Employer perception of distance to transit impedes implementation of onsite sales of transit passes or tokens, transit/pool subsidies, both parking and transit/pool deductions, and discount brokering of transit passes.

\section{Table 1. Distance to Public Transit as a Barrier to Offering Commute Benefits}

\begin{tabular}{lrrr|lrrr}
\hline \multicolumn{2}{c}{ Phase 1 } & & & \multicolumn{4}{c}{ Phase 2 } \\
\hline Commute Benefit & \multicolumn{1}{c}{$\chi^{2}$} & $\delta \%$ & c & Commute Benefit & $\chi^{2}$ & $\delta \%$ & c \\
\hline GRH & 6.790 & $20 \%$ & $9 \%$ & GRH & 9.630 & $27 \%$ & $6 \%$ \\
Transit Sales & 23.258 & $36 \%$ & $6 \%$ & Transit Sales & 15.194 & $29 \%$ & $8 \%$ \\
T/P Subsidy & 24.752 & $40 \%$ & $3 \%$ & T/P Subsidy & 6.411 & $24 \%$ & $5 \%$ \\
T/P Deductions & 4.946 & $22 \%$ & $5 \%$ & T/P Deductions & 8.062 & $29 \%$ & $3 \%$ \\
Parking Deductions & 16.553 & $41 \%$ & $2 \%$ & Parking Deductions & 8.062 & $29 \%$ & $3 \%$ \\
Discount T/P & 8.762 & $33 \%$ & $2 \%$ & Discount T/P & 6.944 & $29 \%$ & $2 \%$ \\
Brokering & & & & Brokering & & & \\
\hline Average & 14.177 & $32 \%$ & $4 \%$ & Average & 9.051 & $28 \%$ & $4 \%$ \\
\hline
\end{tabular}


To assess employer concern of distance to transit, perception of this barrier was cross-tabulated with actual employer geographic location (see Tables $2 \mathrm{a}$ and $2 \mathrm{~b}$ ). A map of Phase 2 results is given in Figure 8.

\section{Table 2a. Perceived and Actual Distance to Transit in Phase 1}

Geographic Location \& Perceived Distance toTransit as Barrier, Phase 1

\begin{tabular}{|lll|r|r|r|r|}
\hline & & & \multicolumn{3}{|c|}{ Transit Barrier P1 } & \\
\cline { 4 - 7 } & & $\begin{array}{c}\text { No } \\
\text { Influence }\end{array}$ & $\begin{array}{c}\text { Some } \\
\text { Influence }\end{array}$ & $\begin{array}{c}\text { Strong } \\
\text { Influence }\end{array}$ & Total \\
\hline Geographic Location & Rail Core & $\mathrm{n}$ & 47 & 9 & 2 & 58 \\
& & $\%$ & $81.0 \%$ & $15.5 \%$ & $3.4 \%$ & $100.0 \%$ \\
\cline { 2 - 7 } & Transit Zone & $\mathrm{n}$ & 126 & 46 & 54 & 226 \\
& & $\%$ & $55.8 \%$ & $20.4 \%$ & $23.9 \%$ & $100.0 \%$ \\
\cline { 2 - 6 } & Non-Transit Zone & $\mathrm{n}$ & 32 & 23 & 49 & 104 \\
& & $\%$ & $30.8 \%$ & $22.1 \%$ & $47.1 \%$ & $100.0 \%$ \\
\cline { 3 - 7 } Total & & $\mathrm{n}$ & 205 & 78 & 105 & 388 \\
& & $\%$ & $52.8 \%$ & $20.1 \%$ & $27.1 \%$ & $100.0 \%$ \\
\hline
\end{tabular}

Table 2b. Perceived and Actual Distance to Transit in Phase 2

Geographic Location \& Perceived Distance toTransit as Barrier, Phase 2

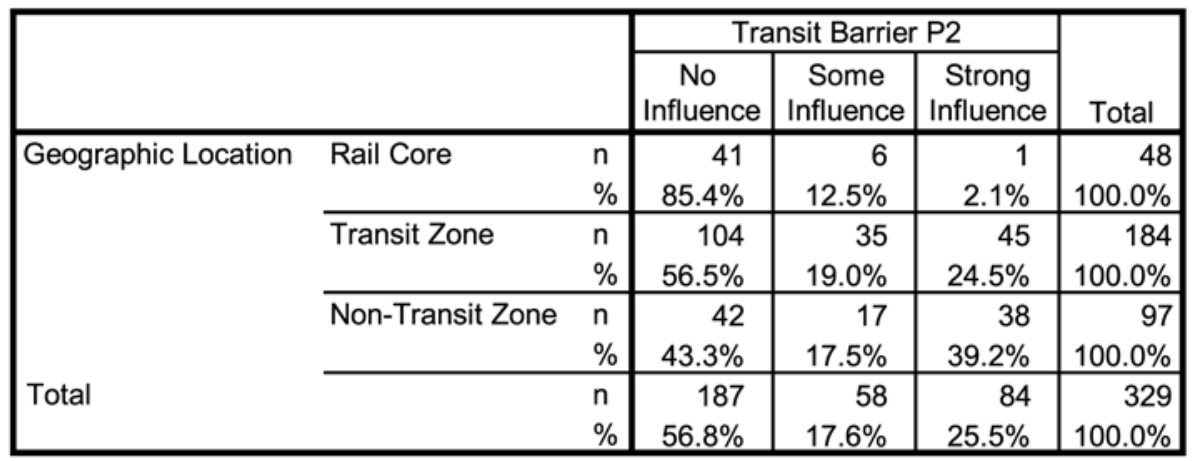




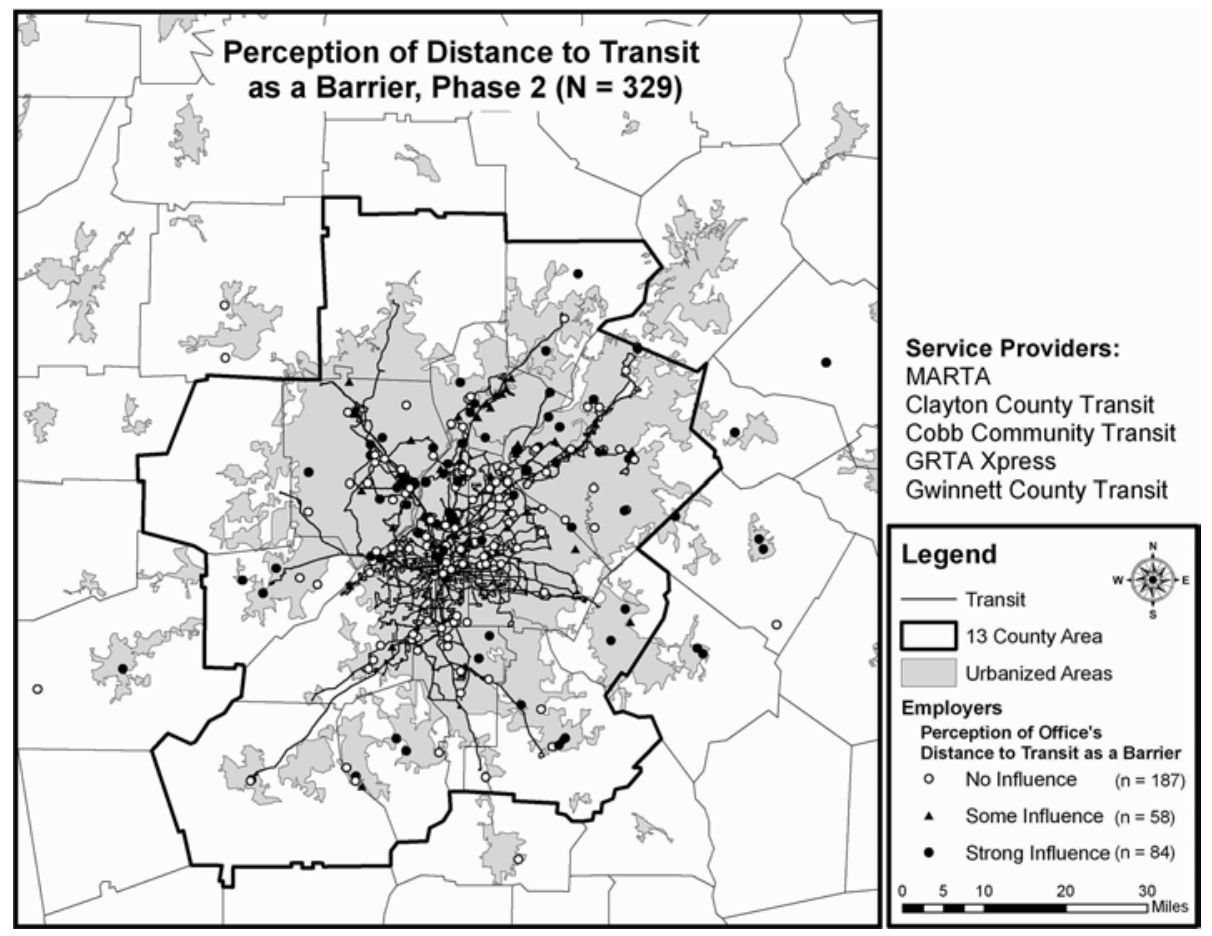

Figure 8. Perceived and Actual Distance to Transit

Generally, employers located near transit report no influence of distance to transit as a barrier. However, many employers who appear to have good access to transit claim not to. This finding is the subject of ongoing research that will treat accessibility to transit in more detail. Employers located outside the transit service area who report no influence might dismiss transit altogether. A policy implication here is to target transit-related EBTR strategies in transit service areas, which is already underway.

\section{Onsite Transit Sales}

The third finding involves barriers to offering onsite sales of transit passes or tokens. Specifically, these barriers are "potential conflicts with organization operations," "high cost to our organization," "equity issues across types of employees," and "lack of government incentives." Table 3 indicates that all four barriers were significant in both phases by the $\chi^{2}$ test. 
The negative difference factor $(\delta \%)$ indicates that employers who do offer transit sales are more likely to regard these barriers as influential than employers who do not offer this benefit. That is, employer implementation of onsite transit sales appears to increase employer perception of conflict with organization operations, high cost, and concerns regarding equity across types of employees. Development of government and transit agency strategies designed to reduce the burden on employers associated with offering onsite sales of transit passes should probably be a high priority.

Table 3. Barriers to Onsite Transit Sales

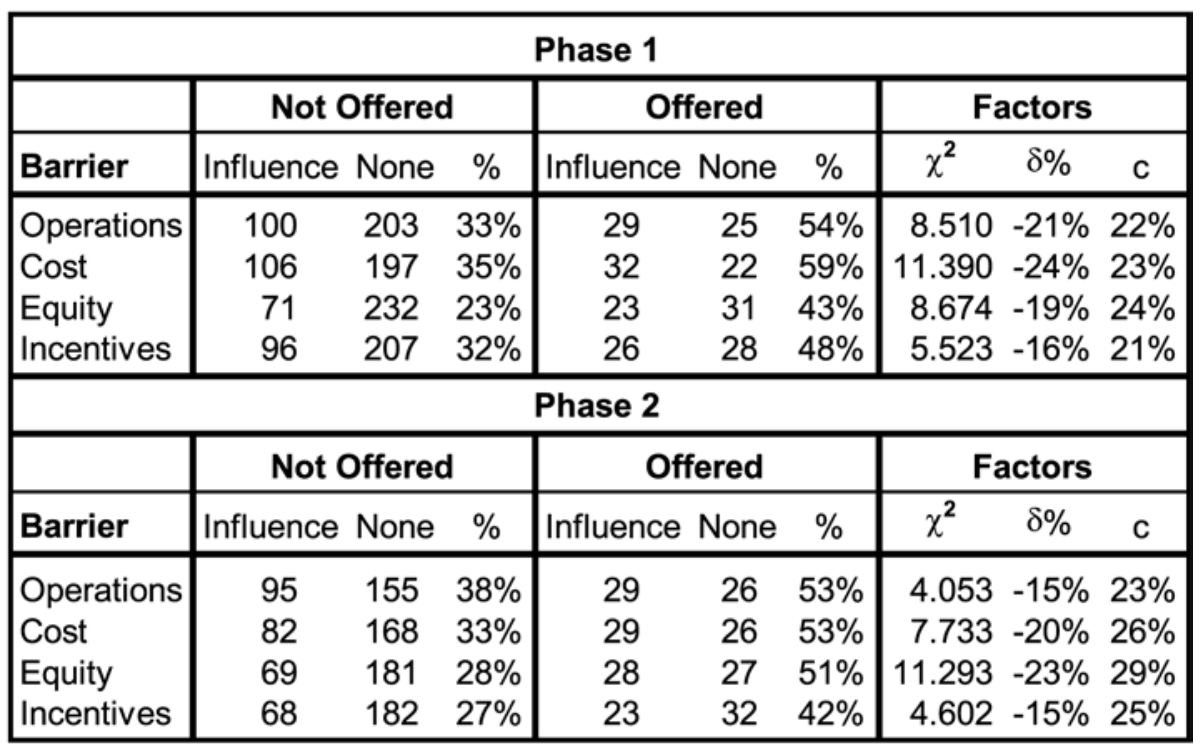

Also noteworthy, in both phases, high regard for the preventative influence of "equity issues across types of employees" is correlated with low levels of offering "employer-subsidized bus, rail or vanpool passes."

\section{Conclusions}

The survey results reported in this article indicate that the promotion, coordination, and service efforts of the CAC and TMAs to member employers are cor- 
related with higher levels of strategy implementation among members. Whether these employers are self-selected into organizational membership remains somewhat uncertain. However, these results are very encouraging.

Internal employer barriers, however, still appear to be significant with respect to implementing incentives. Employers commonly perceive that strategies yield minimal benefits, that their employees lack participation interest, and that upper management will not provide support for employer trip reduction programs.

Employers also regard the distance of their work location to transit as a significant barrier to implementing trip reduction programs. On average, only 4 percent of companies that regard distance to transit as a barrier offer any transit-related benefit. Implementation of onsite sales of transit passes is associated with increased employer perception of conflict with organization operations, high cost, and concerns regarding equity across types of employees. Development of government and transit agency strategies designed to reduce the burden on employers associated with offering onsite sales of transit passes should probably be a high priority.

Given these transit results, additional research efforts should better define acceptable distances to transit and the relationship between employer-perceived and actual distance to transit. Educational initiatives on transit accessibility should be directed toward employers within acceptable transit zones. In addition, employers located an unacceptable distance from transit should not be encouraged to offer transit-related benefits. Such work would also be useful in the planning of future regional transit. Employer-specific choice set analysis, such as that underway in the Commute Atlanta project, would provide a better picture of transit accessibility. Research into the equity impacts associated with employer commute options strategies appears warranted based on the stated concerns of industry in the 2003 and 2005 surveys. Further research is needed to assess trends in employer perception of subsidies on potential conflict with organization operations.

Given that there was no significant change in CAC membership in the samples, advertising campaigns may not have increased employee and employer interest in commute options programs between 2003 and 2005. It is acknowledged that the ECO survey sample may not have captured effects of recent recruitment efforts by CAC contract employees that target sector- and location-specific employers. Nevertheless, as these programs continue to expand in Atlanta, it will become paramount to implement monitoring and survey efforts designed to assess the actual effect of implemented incentives on employee travel behavior. 


\section{Endnotes}

1 This assumes where an employer implements a program, all employees are aware.

${ }^{2}$ Another possibility is employer awareness.

${ }^{3}$ Some of the analysis in this article contains the 19 records identified and deleted in 2006. The calculations were not rerun after the cleaning process in the interest of time, because the impact of these records is negligible given the sample size for each analysis.

\section{References}

Clean Air Campaign. 1999. A framework for cooperation to reduce traffic congestion and improve air quality.

Center for Transportation and the Environment. 2003. Evaluation of the effectiveness of programs contained in the "framework for cooperation to reduce traffic congestion and improve air quality." Phase Three, FY2002 Atlanta TDM Framework Final Report.

Dehart-Davis, Leisha, Chunxia Feng, and Randall Guensler. 2004. Atlanta employer commute options survey report of final results: For GDOT and FHWA.

Dehart-Davis, Leisha, and Randall Guensler. 2005. Employers as mediating institutions for public policy: The case of commute options programs. Policy Studies Journal 33 (4):675-697.

Dill, Jennifer. 1998. Mandatory employer-based trip reduction: What happened? Transportation Research Record: Journal of the Transportation Research Board (1618):103-110.

Feng, Chunxia, Leisha Dehart-Davis, and Randall Guensler. 2005. Survey design and preliminary results for Atlanta employer commute options survey. Paper read at 98th Annual Meeting CD-ROM, June 2005, Pittsburgh, PA.

Finke, Timo, and Eric Schreffler. 2004. Using multiple assessment levels for evaluating transportation demand management projects: Monitoring and evaluation toolkit. Transportation Research Record: Journal of the Transportation Research Board (1864):135-143. 
Guensler, Randall. 1998. Increasing vehicle occupancy in the United States. Paper read at L'Avenir Des Deplacements en Ville (The Future of Urban Travel), Lyon, France.

Hendricks, Sara J., and Ajay Joshi. 2004. Commuter choice program case study development and analysis. Tampa, FL: Center for Urban Transportation Research. University of South Florida.

Henry, Gary T., and Craig S. Gordon. 2003. Driving less for better air: Impacts of a public information campaign. Journal of Policy Analysis and Management 22 (1):45-63.

Higgins, Thomas J. 1996. How do we know employer-based transportation demand management works? The need for experimental design. Transportation Research Record: Journal of the Transportation Research Board (1564).

Horner, Mark W. 2004. Spatial dimensions of urban commuting: A review of major issues and their implications for future geographic research. The Professional Geographer 56 (2):160-173.

Institute of Transportation Engineers and COMSIS Corporation. 1993. Implementing effective employer-based travel demand management programs. Washington, D.C.

Li, Hainan, Randall Guensler, Jennifer Ogle, and J. Wang. 2004. Using global positioning system data to understand day-to-day dynamics of morning commute behavior. Transportation Research Record: Journal of the Transportation Research Board (1895).

McGovern, Enda. 2005. Social marketing applications and transportation demand management: An information instrument for the 21st Century. Journal of Public Transportation 8 (5):1-24.

Meyer, Michael D. 1997. A toolbox for alleviating traffic congestion and enhancing mobility. Washington, DC: Institute of Transportation Engineers.

- - - 1999. Demand management as an element of transportation policy: Using carrots and sticks to influence travel behavior. Transportation Research Part A 33:575-599.

Ogle, Jennifer. 2005. Quantitative assessment of driver speeding behavior using instrumented vehicles. Atlanta, GA: Civil and Environmental Engineering, Georgia Institute of Technology. 
Rye, Tom. 1999a. Employer attitudes to employer transport plans: A comparison of UK and Dutch experience. Transport Policy 6:183-196.

- - . 1999b. Employer transport plans-A case for regulation? Transport Reviews 19 (1):13-31.

Winters, Philip L., Sara J. Hendricks, and Elizabeth Stutts. 2003. Quantifying the business benefits of TDM. Tampa, FL: National Center for Transit Research.

\section{About the Authors}

KAI ZUEHLKE (kai@gatech.edu) is a graduate research assistant in the School of Civil and Environmental Engineering at the Georgia Institute of Technology. He is studying urban transportation planning, and working toward dual M.S. in civil engineering and city and regional planning degrees. His research focuses on employer incentives, commute mode choice, and individual travel behavior. Prior to attending Georgia Tech, Mr. Zuehlke earned a B.S. in engineering science and mechanics from Virginia Polytechnic Institute and State University.

RANDALL GUENSLER (randall.guensler@ce.gatech.edu) is a professor in the School of Civil and Environmental Engineering at the Georgia Institute of Technology. Since arriving at Georgia Tech in 1994, Dr. Guensler's main research focus has been the development of new monitoring and modeling tools to assess the air quality impacts of transportation policies.

Dr. Guensler is the director of Commute Atlanta, a joint value pricing initiative sponsored by the Federal Highway Administration and Georgia Department of Transportation. In addition to allowing study of consumer response to road pricing experiments, Commute Atlanta's second-by-second vehicle speed, position, and engine operating data have led to research on analysis of speeding, journey-to-work route choice, trip chaining, activity-based demand, household trip-making variability, household and vehicle range of travel, long-distance travel, freeway operations, engine load, start and soak distributions, and transit bus operations.

Dr. Guensler was the chairman of the Transportation Research Board committee on Transportation and Air Quality from 1997 to 2002. From 1995 to 2001, he served on the Environmental Protection Agency's Mobile Source Technical Advisory Subcommittee. Over the past 10 years, he has served on various National Academy of Sciences committees and panels charged with the assessment of vehicle emissions impacts and identification of research needs. 